2017-08-21

\title{
Themes in the supervision of social care students in Ireland: Building resilience
}

Fiona McSweeney

Technological University Dublin, fiona.mcsweeney@tudublin.ie

Follow this and additional works at: https://arrow.tudublin.ie/aaschlanart

Part of the Other Social and Behavioral Sciences Commons, and the Social Work Commons

\section{Recommended Citation}

McSweeney. F. (2017). Themes in the supervision of social care students in Ireland: building resilience. European Journal of Social Work, DOI: 10.1080/13691457.2017.1366428

This Article is brought to you for free and open access by the Languages at ARROW@TU Dublin. It has been accepted for inclusion in Articles by an authorized administrator of ARROW@TU Dublin. For more information, please contact arrow.admin@tudublin.ie, aisling.coyne@tudublin.ie,gerard.connolly@tudublin.ie.

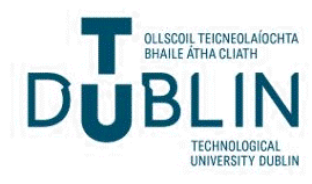




\section{Themes in the supervision of social care students in Ireland: Building resilience}

The field placement is core to the education of social care practitioners and practice teachers' behaviours influence the learning and development of future practitioners. However the practice teacher role is complex with responsibilities to the agency, clients and the student (Davys \& Beddoe, 2000). Twenty practice teachers were interviewed individually about their views of their role, in particular what they saw as most and least important. Inductive thematic analysis resulted in the identification of five themes 1) the nature of the work; 2) acceptance of individuality; 3) commonality and differences from staff; 4) focus on positives and 5) practice involves planning, doing and reflecting. Although resilience was not specifically mentioned the findings indicate that supervisors focus on ways of working with students that proactively encourages resilience in line with Grotberg's (1995) model, sending students messages in relation to I am (respected and respectful of others), I have (support; skills and strengths), I can (contribute). This study expands on the literature by informing us how practice teachers interact with students to promote resilience. It is suggested that Grotberg's model forms the basis of a new paradigm to ensure the development of future resilient practitioners.

Keywords: social care students; practice teacher; field placement; supervisory relationship; resilience; acceptance; competence; Grotberg.

\section{Introduction and Literature Review}

Social care work involves the provision of professional care, protection and advocacy to individuals and groups who 'experience marginalisation, disadvantage or special needs' (Social Care Ireland, 2016, n.p.). Social care practitioners in Ireland are employed in a variety of services such as residential care for young people, aftercare, youth work, day and residential services for people with intellectual disability, sensory disability and mental health issues as well as services for people with addiction issues and those experiencing homelessness.

Although there are commonalities between social care work and social work, for example supporting those in need, empowerment and enhancing the well-being of clients 
(Irish Association of Social Workers, 2016; Social Care Ireland, 2016), social care work emphasises the use of 'shared life-space opportunities to meet the physical, social and emotional needs of clients' (Social Care Ireland, 2016, n.p.) while the principal role of social workers is to intercede between 'public legislation and the private individual' through the regulation and protection of people (Skehill, 2003, p.151). In Ireland the professions are distinct and education is separate.

Education for social care involves a three or four year degree including at least 800 field placement hours, in a minimum of two social care agencies. Not only is the placement essential for students' education but also benefits agencies by bringing new ideas and knowledge, challenging practice and increasing reflection (Globerman \& Bogo, 2003; Barton, Bell, \& Bowles, 2005).

In the placement a practice teacher is appointed to the student who agrees a learning contract with the student, conducts supervision and monitors progress with regard to interpersonal and professional skills, integration of theory with practice, conducting interventions with clients, openness to learning and use of supervision (Irish Association of Social Care Educators, 2009).

\section{Practice teacher role}

While practice teachers are essential in the education of future social care workers (Simpson, Mathews \& Crawford, 2014) their role is complex and multi-faceted (Davys \& Beddoe, 2000). Research indicates that it involves direct teaching (Lefevre, 2005), facilitating students to practise professional skills (Fortune, Lee, \& Cavazos, 2007) as well as modelling good practice to ensure that students' practice coheres with professional values (Thompson, 2006; Hughes, 2011). Providing students with a basis to understand practice through integrating theory with practice is also involved (Fortune \& Kaye, 2003), although due to the variety of 
possible theoretical frameworks that can underpin practice this can be difficult (Homonoff, 2008; Forte \& LaMade, 2011) as well as the possibility that practitioners use theory subconsciously (Higgins, 2014). Reflection can help with this integration (Staempfli, Kunz, \& Tov, 2012). While reflection is important in social care work (O’Neill, 2009) students find it difficult (Halton, Murphy, \& Dempsey, 2007) and support is appreciated (Wilson, 2013).

Regarding the relationship with the practice teacher Brodie and Williams (2013) found students value someone who is approachable, honest and non-judgemental. Also important is showing interest in the student and listening to students' suggestions (Knight, 2001), treating students as individuals so their learning is appropriately supported (Nye, 2007), making expectations clear (Davys \& Beddoe, 2000), setting goals in a collaborative way (Miehls, Everett, Segal, \& du Bois, 2013) and building students' confidence (Wilson, O’ Connor, Walsh, \& Kirby, 2009) as students are likely to 'encounter anxiety, self-doubt and stress as they enter field work' (Harr \& Moore, 2011, p.354). While students appreciate being informed of agency policies (Miehls et al., 2013), Wilson and Kelly (2010, p.2432) criticise reducing 'professional practice to the routine following of agency policy and procedures.' Supportive relationships allow the student to partake fully in the agency thereby learning more (Vågstǿl \& Skǿien, 2011) and accept critical feedback (Bogo, 2006). Critical feedback builds motivation and self-efficacy when learning goals have been established, the student is encouraged to self-evaluate, it is balanced with positive feedback (Abbott \& Lyter, 1999), is practical (Bogo, 2006) and honest (Brodie \& Williams. 2013). However practice teachers can be reluctant to give students negative feedback in case it damages the relationship (Bogo, Regehr, Power, \& Regehr, 2007). Some propose reframing mistakes as learning opportunities to foster students' development (Beddoe, Davys, \& Adamson, 2013). Also it is suggested that focusing on successful interventions and outcomes will increase compassion satisfaction and buffer against compassion fatigue (Harr \& Moore, 2011). 


\section{Compassion fatigue, vicarious trauma, stress}

The necessity of being empathetic towards clients can contribute to compassion fatigue, particularly with students as they may find it more difficult to 'set healthy boundaries with clients' (Harr \& Moore, 2011, p.352) due to inexperience (Radley \& Figley, 2007). Also as students may not have developed strategies to process exposure to clients' distress (Litvack, Mishna, \& Bogo, 2010) they are susceptible to vicarious trauma. Grant (2014) attributes this to students having high levels of empathy but not of empathetic reflection and reflective communication. Furthermore students may not accept the validity of their emotional reactions to practice situations, viewing them as 'irrational or undesirable,' or unprofessional, requiring them to be suppressed (Grant \& Kinman, 2013, p.355; Rajan-Rankin, 2014), rather than recognising the role involves emotionality alongside the 'knowing and doing' (Kearns \& McArdle, 2012, p.392). Although vicarious trauma can be lessened when a supportive relationship exists with practice teachers (Knight, 2010), students' views of emotionality may inhibit support seeking. However practice teachers admit they may underestimate the impact on students of hearing and witnessing clients' distress and the resurfacing of students' own painful experiences (Barlow \& Hall, 2007). Also found to be mediated by support is fear of violence from clients (Criss, 2010). While practice teachers consider student safety they note the difficulty in preparing students for 'managing potentially violent situations' (Barlow \& Hall, 2007, p.406). These factors contribute to stress, although job satisfaction and feelings of personal accomplishment are also evident in helping professions (Kinman \& Grant, 2011). Students may suffer more from stress than workers due to being challenged by the reality of the work and the level of clients' problems (Beddoe et al., 2013). Due to reported levels of stress research has more recently focused on resilience as a protective factor.

\section{Resilience}


While resilience has been operationalised and theorised about in different ways common to these is that it protects 'individuals from the negative appraisal of stressors' (Fletcher \& Sarkar, 2013, p.16). Initially resilience research focused on individual traits associated with positive adaptation despite adversity but has shifted towards examining resilience as a dynamic process. Grotberg (1995), envisions resilience as a capacity that develops from receiving positive information from others in relation to competency, acceptance and social support. Palma-Garcia and Hombrados-Mendieta (2014) argue that this model is particularly suitable to examine resiliency in the helping professions as evidence suggests that confidence and competency develop by responding to challenges in the work. They found that social work students' self-reports of personal competency and acceptance of self and others increased as they progressed through the educational programme. Social workers scored higher than students and seniority was associated with even higher scores.

While some research in relation to social work has identified strategies and skills associated with resilience in students these mainly concentrate on what the individual student can do rather than acknowledging that the education of future practitioners occurs within relationships with educators in the classroom and field placement. This individual focus, Considine, Hollingdale, and Neville (2015), associate with a neo-liberal ideology that is neglectful of the social embeddedness of people. For example Rajan-Rankin (2014, p.2429) suggests resilience be conceptualised as a 'learnt skill which can and should be taught as part of social work training.' Kinman and Grant (2011), based on positive correlations between self-report measures of emotional intelligence, social competence, perspective taking and empathetic concern, suggest that students be helped develop these skills as part of their education. They discuss training workshops designed to develop these competencies and how those with less developed skills can be supported to enhance them (Grant \& Kinman, 2012). 
Also required is students to appreciate their need to be resilient (Grant, Kinman, \& Baker, 2015).

Other research explores practice teachers' views of what contributes to resilience in students. Distinguishing between personal and professional views and values so that a clear boundary between the personal and professional self is maintained, having dealt with their own personal issues, taking responsibility for self and learning and keeping the aim of the work and its theoretical rationale in mind are discussed (Beddoe, et al., 2013; Adamson, Beddoe, \& Davys, 2014). As experienced social workers have a more sophisticated understanding of resilience than students, viewing it as involving the interaction between the person's characteristics and a supportive environment and requiring constructive management, Grant and Kinman (2013) suggest that are they ideally positioned to help students enhance their resilience. Practice teachers see their role in promoting resilience as involving modelling self-care, encouraging self-awareness, making theoretical concepts concrete and providing supervision (Beddoe, et al., 2013). McAllister and McKinnon (2009) go further and suggest that professional preparation in the health professions should include aspects of transformative education in fostering resiliency. They advocate the inclusion of critical and constructive analysis of practice, encouraging creativity and pride in one's work, praising success, learning from one's own and other's practice and correction of errors.

\section{Conclusion}

Research indicates the expanse of the practice teacher role including teaching, modelling good practice, provide opportunities for the student to practise skills, helping students understand and link underpinning theoretical frameworks with practice, as well as facilitating reflection. Research has also focused on building resilience in students to enable them to cope with the stresses of the work. This research has focused on the student as an individual and 
recommending training as well as exploring practice teachers' views of what resilience is and how it can be developed in students. The current research develops discussion of this topic by providing detail of how practice teachers in social care engage with students to build their resilience. What is particularly interesting is that its aim was to explore practice teachers' views of their role and resilience was not considered nor discussed during the design and data collection. However inductive thematic analysis of the data revealed that practice teachers worked with students in ways that promoted their acceptance of themselves and others, built self-efficacy and tailored their support to the individual.

\section{Methodology}

The methodological approach utilised was Q methodology. The rationale for this and the findings from the Q methodological analysis are reported elsewhere (McSweeney, 2017). This involved presenting participants with 31 statements about the role of the practice teacher, generated from literature on supervision and discussion with social care students and a social care tutor and asking them to rank them in a particular format in relation to their view of how important and unimportant they were to their role. The statements covered areas such as: the integration of theory and practice; college work; monitoring learning and providing feedback; agency policies and clients' needs; provision of support; reflective practice promoting self-awareness and self-assessment.

\section{Participants}

Ethical approval was received from the author's institution prior to contacting potential participants. Purposive sampling was used to ensure diversity with regard to areas of social care and experience as both social care workers and practice teachers. Participants were accessed through previous contact with the researcher in her role as college tutor, through colleagues and the practice teachers themselves. Initial contact was made through a letter 
providing information about the research and an invitation to participate. For the 20 people who responded a time and location for the interview was arranged. Three participants worked in residential care for young people, three in aftercare services, two in homeless services, two in addiction services, two in domestic violence services, two with people with sensory disabilities, two in intellectual disability services, two in youth work, one in a mental health service and one in a service for people with chronic illness. The number of students supervised ranged from one to over 80 and years worked in social care ranged from two to 37. Participants are identified in the findings by the order in which they were interviewed and their area of work, for example 9ID indicates the ninth interview and the participant works in the area of intellectual disability.

\section{Procedure}

A list of the 31 statements was emailed to each participant a week before the interview.

Before the interview participants were reminded of their rights to anonymity in publications, confidentiality and withdrawal and signed a participant consent form. During the interview the participants sorted the statements in relation to their view of their relative importance and unimportance to their role and were encouraged to talk about each one. Interviews were audio-recorded, transcribed and the transcription sent to each participant.

\section{Thematic analysis}

While the Q analysis had the advantage of identifying commonality in what aspects of their role the participants deemed to be more and less important it is accepted that the method used to analyse data constructs a particular knowledge about a topic (Mason, 2002). Therefore examining the data from a different approach can lead to greater insight. Q analysis involves a factor analysis of the patterns of rankings between participants and while what the participants said about the statements is used to interpret the meaning of the underpinning 
factors it is essentially quantitative. A combined approach to analysis has been recommended to fully explore data generated in Q methodological studies and thematic analysis is considered to be complementary as both focus on the subjectivity of people's views (Shinebourne \& Adams, 2007; Lazard, Capdevila, \& Roberts, 2011). Also forcing the ranking of statements into a particular pattern with Q methodological research has been critiqued for creating shared viewpoints rather than revealing them (Kampen \& Tamás, 2014).

The thematic analysis of interview transcripts was approached with an open mind thus was inductive (Braun \& Clarke, 2006). Analysis focused on participants' interpretation and explanation of each statement and their consideration of the behaviour specified in their interactions with students. The process outlined by Braun and Clarke (2006) was used. Interview transcripts were read several times and coded. Codes were combined and related to potential themes, reviewed several times and named. Five themes were identified and then considered for overarching meaning.

\section{Findings}

The five themes identified in the data and their link to Grotberg's factors is illustrated in Table 1. 
1) Nature of social care work necessitates

\section{Support \\ Openness to learning and practice approaches \\ Guidance by policies}

2) Acceptance of individuality

$$
\begin{aligned}
& \text { Students } \\
& \text { Staff } \\
& \text { Clients }
\end{aligned}
$$

3) Commonality and differences with practitioners

5) Practice involves
4) Focus on positives
Value students' contribution

Build confidence

Focus on strengths

Correct in a positive way

Encourage balanced self-evaluation

\section{Planning \\ Doing \\ Reflecting}

\section{Resilience factor}

I have

\section{Support from my practice teacher}

Polices to guide and put limitations on my behaviour

I can

Communicate my feelings to my practice teacher

I am

Flexible and adaptable

I am

Respected for who I am

Supported in a way that suits me

A person who respects others

I am

A student so still learning

Responsible for my behaviour

I have

Support for my learning

I can

Make a positive contribution (self-efficacy)

Evaluate my behaviour

I have

Skills and strengths

Limits to my behaviour

I am

Competent in planning, implementing and interacting

I have

\section{Role models}

I can
Understand my behaviour and that of others

Generate new ideas and ways of doing things 


\section{Theme 1- Nature of social care work - support, openness, policies}

Participants related the necessity of being supportive to students to the nature of social care work. They acknowledged the emotionality involved in the work and the validity of students reactions as recommended by Kearns and McArdle (2012), accepting that the 'reality of residential care work' (1RC) or 'dealing with people in crisis' (6HS) is very challenging for students (Beddoe et al., 2013). Participants were clear about sending the message to students that they were available to provide social support and the student could communicate their feelings to them:

I think it's really important that students get an idea that they can come and they can talk to you because if you don't have that they're left with all these feelings. They're left holding them. And they're a lot of time unable to deal with that and it can affect their home life. (5AC)

Sources of difficulty requiring support included were clients' behaviours $(n=6)$, the possibility of students' suffering from vicarious trauma from hearing clients' experiences $(n=4)$, compassion fatigue $(n=2)$ or arousing unresolved feelings $(n=1)$, common with literature (Litvack et al., 2010; Harr \& Moore, 2011). The volatility of the social care environment was referred to by two participants. Support was also required due to the intensity of the relationship-based work $(n=3)$, managing boundaries $(n=4)$, adapting to shift work $(n=2)$ and managing paperwork $(n=1)$.

Eight participants spoke of the need for social care practitioners to be always open to new learning indicating to students the need for being flexible and adaptable. Reasons given were societal changes, 'best practice is current best practice not absolute' $(20 \mathrm{MH})$, 'none of us are the finished article' (6HS) and 'the day you stop [learning] is the day you should hang up your boots' (5AC). Connected, but more specific, is being open-minded to different approaches to practising, discussed by eleven participants. The most common reason $(n=7)$ 
given was that as clients are different so should the ways of working with them be, with two people also including differences among staff. Four participants noted the variety of theoretical frameworks that could be utilised. Also referred to was desired outcomes could be achieved through different ways and the dangers of tunnel vision:

This is the way it's done and this is how it's done and it's worked so why would I change it. And yet quite possibly no but let's look at. Could it be better? Let's look at something else that's out there that's different. (8RC)

Another participant emphasised that any practice approach used should fit with the overarching ideology of youth work.

Policies in social care were seen as important for guiding practice $(n=16)$, protecting clients and staff $(n=9)$ and being reflective of the ethos of the organisation $(n=7)$. Three participants pointed out their statutory nature. Their approach to informing students about policies varied from ensuring they had 'a comprehensive overview of how the policy and procedure framework operates here' (10ID), without which 'they kind of muddle through a bit' (5AC) at the beginning of the placement, indicative of viewing them as necessary ways to guide students' behaviour and clarify expectations as noted by Davys and Beddoe (2000). Others referred to the amount of policies and said that students would initially be briefed on the essential ones and directed towards where they are kept:

On the first day we sit them down with the policies and procedures and tell them, like this is three hundred pages. And we just inform them that you are not expected to learn this off but you are expected to know where it is and basically expected to know what areas it covers. (12HS)

\section{Theme 2 - Acceptance of individuality - students, staff and clients}

All participants stressed the importance of accepting students as individuals, giving various reasons. Acceptance was explained to be part of the ethos of social care practice by seven 
participants, although three qualified this by noting that they had a role in judging the students' practice:

We spout that we should be non-judgemental with our customers or clients or whatever. Same goes for our colleagues, or students or whoever else comes in. (6HS)

Participants also spoke of the need to adapt the way they worked with students in relation to their level of experience and maturity $(n=4)$; the personal challenges a student may be encountering $(\mathrm{n}=5)$ as well as the different goals, interests and skills students have in relation to the placement $(n=10)$. Five participants specified the centrality of the use of self in practice and two that everyone 'deserves a fair crack' (1RC). Three participants said that being nonjudgemental was necessary for a relationship to be built and the student to learn, in agreement with Vågstǿl and Skǿien (2011):

If you're judgemental from the beginning it's going to fail. You're not going to have a good relationship. They're not going to learn anything and they're just going to see things from a punitive sort of way. It would be like being judgemental towards the young people. If you want open-mindedness you have to practise it yourself. (5AC)

Participants also discussed the need for students to accept the individuality of staff and clients. Eight participants referred to the importance of students being exposed to and accepting other people's style of working to encourage open-mindedness towards different ways of achieving the same goal $(n=8)$, particularly in a multi-disciplinary team $(n=1)$, due to need for teamwork in practice $(n=2)$ and to help them find their own practice style $(n=2)$, incorporating respect towards other individuals with the availability of role models.

Though as will be discussed below there was variation among participants about the amount of information students were given about clients, the individuality of clients' needs and the provision of an individualised service was commented on $(n=8)$. Four participants differentiated between clients' needs and wants in terms of the service. Also outlined were 
differences between clients' values and beliefs to those of students and staff $(n=3)$, the need to be aware of the influence of clients' past experiences on their current behaviour $(n=4)$ and to listen to clients' wishes $(\mathrm{n}=6)$ :

That's relating back to the young people in here and why they're here and what they're looking for. And talk about their needs so that the students are aware of why they might be acting or behaving in a certain way. And the needs that they have. (11YW)

Five participants brought up the importance of not only being non-judgemental towards clients but also being aware of the impact of societal stereotypes and stigma on them, further cementing the message of respecting others, as well as indicating influences on clients' behaviour:

That would be paramount in actually teaching the students, about the stigma within society. About the discourses within society to give them some understanding of how that impacts on the client's identity. And you know the students are open enough to say it to me that they've had preconceived ideas about addicts, heroin addicts. (13AS)

\section{Theme 3 Commonality and differences between students and practitioners}

In differentiating between practitioners and students the limitation of the placement length was seen as a factor $(n=3)$ so students only get 'a snapshot of what the work is about' (1RC). This, along with protecting the confidentiality of clients, precluded students from knowing certain information about clients $(\mathrm{n}=2)$.

While all participants acknowledged the learning involved in placement, half the participants used phrases such as 'still learning' or 'only learning' in relation to students, linking this to lesser expectations and responsibilities than staff. The learning aspect required the practice teacher to structure and monitor learning, with 'space to reflect' (11YW), although the student was seen by some to have a responsibility in their own self- 
development, suggesting that the work is seen as more than just following policy (Wilson \& Kelly, 2010):

Well obviously he's here to learn so if he's not learning something on a regular basis he's not going to be able to competently deal with families and clients and their needs. Though it is about him developing himself and learning the nature of the work. (16DV)

Three participants stated that regardless of being a student a level of initiative and effectiveness was expected:

It's the same with all the staff, student, it doesn't matter. They have to be operational. They have to be the best they can be at all times. (10ID)

Three participants explicitly mentioned preparation for work and placement being an opportunity 'to gear the student up to a stronger awareness of what these competencies are so they are in a position then to go for interview, get employment and be good at their job' (10ID); 'trying to always get that mix right between work and working environment but at the same time these are students and they need to be in a learning and encouraging environment'(19AS) and providing 'an opportunity for people to learn about the work role, about the whole world of work' $(20 \mathrm{MH})$. Hence the stated behaviours of the practice teachers inform students that they are still learning and have support in doing this. However students' responsibility for their behaviour was also evident although participants varied regarding the level.

Four participants expressed the view that expectations of accountability for practice needed to be developed and required the support of the practice teacher:

To ensure that they take responsibility is something that you would work on. They wouldn't grasp that straight away. You wouldn't expect them to. Like someone to be accountable from the get go. It is something to build on. [...] I'd see the person needing a lot of support around that. (2AC) 
Another five spoke of accountability as being a learning opportunity and linked with reflective practice. However the remaining eleven participants emphasised the importance of a student being equally accountable for their practice as staff, both negatives and positives and shouldn't use 'the student cap' (3RC) as an excuse for not taking responsibility, although errors are seen as sources of learning, as evident in the literature (Beddoe et al., 2013):

They've learned enough to say okay I ballsed it up. To say that you made a mistake and why you made a mistake and to say that it went well and yeah I did do it well. And to take pride in the fact that it went well and to take learning in the fact that it didn't go well. (15DV)

Theme 4 Focus on positives - value students' contribution, identify their strengths and give positive feedback, even when correcting

Letting students know about their competencies and positive contributions through the generation of new ideas was very evident. As other research (Globerman \& Bogo, 2003; Barton et al., 2005) found, some participants $(n=7)$ explicitly emphasised the contribution of students to the organisation through providing feedback, bringing new learning, energy and ideas as well as specific skills, which could be effectively used to challenge the practice of staff. It was considered important that students are listened to and feel valued:

That's a big thing here that people realise while I'm a student everybody is listening to me. Because they're all seeing that what I'm saying is valued. (20MH)

To ensure that students were comfortable to contribute participants $(n=6)$ talked about building students' confidence through acknowledging their work and encouraging them to make suggestions:

To go you do matter. Your opinion does matter. Use your voice as well and that you are able to, so it's kind of trying to give someone a bit of a boost as well and I think that's just as important. (9ID) 
Building confidence is related to recognising the strengths the students have so that they appreciate them, 'especially if they have a lot to offer' (7YW) "cos sometimes you question. Am I doing alright? Am I doing okay here?' (18CI) and 'every single student has strengths and potential and something to offer' $(6 \mathrm{HS})$ so 'you want to acknowledge that they've done really well' (14SD).

With regard to providing feedback the participants all stressed that it should be provided in a non-judgemental and constructive way. However thirteen of the participants highlighted the need to focus on positive feedback because 'it's hard to know you're doing the right thing. And it is a big part of their learning as well' (7YW) and students 'don't recognise it as being a positive piece of work' (12HS). As practitioners working with clients focus on strengths and positives they also do so with students:

I always tell them what they are good at so they don't come away with a really negative experience. And when we work with the young people in here we never point out their negatives. We always try to steer to their positives so it's the same with anyone who comes on student placements. (11YW)

Three participants pointed out that more positive affirmation was needed in social care work, one mentioning that the social care inspectorate always focused on negatives, hence the need to praise the student:

I think we are too critical of ourselves. So I think it is very much supporting the student. You know you did a really, really good job there on A, B and C. Well done on that. And sometimes that's all that needs to be said or sometimes you might say the next time what do you think about A, B and C. (3RC)

While participants recognised their role included providing feedback on deficits in the students' practice 'because they're not getting anything out of the placement and it doesn't do them any good if they want to work in the area' (5AC), this was explicitly discussed as being 'areas they might like to look at' (1RC) or areas 'we need to work on' (3RC) by seven 
participants. Two others said they would find ways to develop any deficiency without mentioning it to the student while another two said if the student did something 'off the wall' (7YW) they would point it out. It was suggested $(n=4)$ that 'if you have that non-judgemental stance toward them they're much more able to take the criticism' (13AS), concurring with Bogo's (2006) proposal, and correction needed to be done in a caring and honest way 'without kind of the brutality of it' (19AS), as suggested by Brodie and Williams (2013). Six participants noted that shortcomings should become apparent to the student through reflection on practice, thus encouraging students to use reflection to understand themselves. Along with reflection, social care work was seen to involve planning and doing.

\section{Theme 5 Planning, doing reflecting}

Participants spoke about teaching students about care planning for clients $(n=2)$; recognising that plans for clients do not always come to fruition $(n=1)$; ensuring that clients were involved and happy with plans $(n=4)$; that planned interventions were meaningful for the clients $(n=3)$; helping the student turn a suggestion into a plan $(n=3)$ and the importance of being outcome based (n=5) as 'we're not just here to have relationships with the young people but we're actually here to get somewhere with them and there's a purpose to the work' (7YW). Part of the practice teacher's role was to help students implement plans:

He comes up with them and then he just sits there. So it is to try and encourage him to do them. And to figure out how to do them. [...] So it's to facilitate, for him in particular is to get him to work on goals. Don’t just keep coming up with ideas. (17SD)

All participants emphasised the importance of the student being 'an active participant in the placement' (1RC), not 'sitting around and losing out' (9ID). Participants pointed out that it was through interacting with clients that the student understood them: 
Because she spoke about her experiences of coming to the refuge and what that was like so it was good for him to be aware of that and to understand that as well so it was great for him. (16DV)

And:

Challenge their fears in as many ways as well as you know they are coming up against different experiences and different day to day activities that they won't have experienced before. (1RC).

Some participants talked about providing the student with specific tasks $(n=10)$ to guide their learning and help them settle in:

They're in a hands on role maybe serving a meal, helping with preparation and they're finding their feet and listening and learning. And that's more in the early stages which really helps that finding your feet. (18CI)

Others said they expected the student to show initiative $(n=5)$. Three participants stated that through doing students could see theories in action and three highlighted the learning achieved through watching the practice teacher, again emphasising the part of role models. When talking about the students being actively involved three participants particularly emphasised the value of stopping doing to reflect as 'you're going to lose the learning point' (11YW).

Two participants remarked that reflection was difficult, as found by Halton et al. (2007), and all discussed its importance. Reflection was explicitly said to be where the learning occurs by five participants. Participants discussed the importance of reflecting on practice as 'it will be innovative and lead to change' $(20 \mathrm{MH})$, of linking theory and practice through the process of reflection, and reflection increasing self-awareness by examining one's personality and feelings, again helping students to understand themselves. Four participants stressed that reflection should be constructive and include positives and another 
four stated that they may use examples and recount their own experiences of practice if it would help the student reflect, hence providing modelling.

The findings indicate that the practice teachers interviewed work in varying ways with students to promote aspects of Grotberg's (1995) resilience model of I can, I am and I have, without actually voicing the term resilience. As Higgins (2014) points out that practitioners have integrated theory into their practice that they are no longer consciously aware of using it perhaps they have also integrated the values of empowerment and strengths focus into their work with students.

\section{Discussion and Conclusions}

While Palma-Garcia and Hombrados-Mendieta (2014) found that experience in social work and training led to increased resilience the current research elaborates on this by indicating how practice teachers interact with students to develop their resilience. Findings will be discussed in relation to the three elements of Grotberg's (1995) model.

\section{I can}

Rajan-Rankin (2014) encourages educators to recognise the challenges and emotionality that students face in training to be social workers. Participants not only recognised these but also the possibility of students' not being able to process them without their help. They promote resilience through voicing potential difficulties and being available to talk about them, thus providing support. This encourages students to appreciate the emotional element of the work (Kearns \& McArdle, 2012) rather than seeing emotional detachment as being indicative of professionalism (Grant \& Kinman, 2013; Rajan-Rankin, 2014).

While some participants specifically referred to areas where students made a positive contribution to the agency valuing input of students was implicit in all the interviews through 
discussion of the students' skills and strengths and pointing these out to them. This contributes to students' self-efficacy.

As students were encouraged to reflect on and evaluate their own practice they were also encouraged to consider the influences on clients' behaviour and interactions helping them to understand the reasons behind behaviours.

By acknowledging openness to learning different ways of practising, encouraging students to voice their ideas and assisting them in developing and implementing their plans the students' ability to generate new ideas is confirmed.

\section{I am}

Through appreciation of different approaches to practice and the need for practitioners being open to new learning messages about flexibility and adaptability are transmitted to the student. The acceptance of students' ideas and encouraging them to 'use their voice' indicates to them that staff are flexible also.

A strong emphasis on acceptance and respect for people and their individuality was apparent in the data. Since being non-judgemental and positive regard are central to social care work not only are students being told that they are respected as individuals, along with staff and clients, but practice teachers are modelling core values (Thompson, 2006; Hughes, 2011). Nye (2007) proposes that awareness of individuality is important to scaffold learning appropriately and the findings indicate that practice teachers are cognisance of not only personal issues that may affect students but adapt to the level, abilities and interests of the students. Participants also discussed helping students become more aware of their upbringing, experiences and values on their own and clients' behaviour. Alongside this respect for other people was exposing students to and encouraging them to appreciate the different ways of practising among staff. 
Tolerance and appreciation for students not being staff is obvious in the findings.

Although participants spoke about the need for practitioners to be open to learning students were protected to a greater extent and their learning structured and monitored more. The need to reflect as well as do was considered to be necessary for students to learn about themselves in relation to practice as well as fitting theory with practice (Staemplifi et al., 2012). Some participants spoke about making theories more real by providing examples as found by Beddoe et al. (2013). Being held responsible for their practice and behaviour was also seen as contributing to learning and necessary for professional practice, thereby giving students the message of responsibility for their own behaviour, both positive and negative.

Direct teaching about planning and supporting students in planning and implementing their own ideas as well as ensuring that students' were actively involved with clients provided them with knowledge about their competencies in these areas.

\section{I have}

The need to support students is evident in relation to challenges faced and also in relation to supporting their learning, through ensuring appropriate opportunities are provided and facilitating reflection. As Wilson (2013) notes students appreciate assistance with reflection and participants in this study recognise that.

Policies are seen as ways of guiding the behaviour of both practitioners and students thereby informing students of the limitations with regard to what they could do and avoiding putting themselves or others in danger. While the importance of students being aware of organisation and statutory policies is emphasised, what Wilson and Kelly (2010, p.2432) refer to 'routine following' does not appear to be the case as participants refer to students demonstrating initiative, being open to different ways of practising and the individuality of clients. 
That students' have and should appreciate their strengths, skills and knowledge was very evident in the data. There was a lot of focus on positive feedback and encouragement to reassure students about their practice, motivate them and ensure that good practice was praised (McAllister \& McKinnon, 2009).

Limits on behaviour are also set through the practice teacher providing feedback on students' practice, something that other studies have found to be particularly valued by students and considered necessary for the preparation for professional practice by McAllister and McKinnon (2009). Although some participants, in common with the findings of Bogo et al. (2007), expressed reluctance about giving negative feedback to students, others qualified this, referring to the significance of errors made and doing it in a non-judgemental and honest way. Other participants referred to students' ability to self-evaluate to recognise mistakes giving them the message that they can evaluate their own behaviour and building selfefficacy and motivation (Abbott \& Lyter, 1999). That self-evaluation should recognise the positives in practice was very much emphasised as well as the practice teacher providing praise, as recommended by McAllister and McKinnon (2009) to build resilience.

While noting the individuality of ways of practising participants spoke about ensuring that role modelling of their own and other staff's practice was available for students to help them in finding a style of working that suited them.

\section{Conclusions}

As with all research, there are limitations to this study. Although relatively large for a qualitative study the sample size of 20 prohibits generalisation. However the range of backgrounds and experience level of the participants does suggest that promoting resilience when practice teaching students is not specific to individuals, areas of social care or organisations. While accepting that the data was constructed to some extent by the statements 
provided to the participants that focusing on resilience was not considered until the thematic analysis was completed adds strength to the findings. As Ungar (2003, p.85) argues qualitative methods are useful for the discovery of 'unnamed protective processes' in research on resilience. Obviously that the research is solely based on the views of the practice teachers not the students they supervise so confirmation of the extent to which the behaviours the participants say they engage in are done and the impact of these on students cannot be verified. This can be considered to be a limitation that could be rectified by seeking the views of students.

In conclusion, conceptualising resilience as being a capacity that can be built in supportive interactions with others (Grotberg, 1995), this research shows that practice teachers are not only in a position to develop students' resilience (Grant \& Kinman, 2013) but are doing so without consciously referring to resilience. As currently no model exists for practice teachers in social care in Ireland to use as a framework to ensure that resilience is proactively developed it would beneficial to utilise the paradigm provided by Grotberg and examples from these participants for the development of future resilient practitioners. 


\section{References}

Abbott, A.A., \& Lyter, S.C. (1999). The use of constructive criticism in field supervision. The Clinical Supervisor, 17(2), 43-57.

Adamson, C., Beddoe, L., \& Davys, A. (2014). Building resilient practitioners: Definitions and practitioner understandings. British Journal of Social Work, 44, 522-541.

Barlow, C., \& Hall, B.L. (2007). 'What about feelings?' A study of emotion and tension in social work field education. Social Work Education, 26(4), 399-413.

Barton, H., Bell, K. \& Bowles, W., (2005) Help or hindrance? Outcomes of social work student placements, Australian Social Work, 58(3), 301-312.

Beddoe, L., Davys, A., \& Adamson, C. (2013). Educating resilient practitioners. Social Work Education, 32(1), 100-117.

Bogo, M. (2006). Field instruction in social work. The Clinical Supervisor, 24(1-2), 163-193.

Bogo, M., Regehr, C., Power, R., \& Regehr, G. (2007). When values collide. The Clinical Supervisor, 26(1-2), 99-117.

Braun, V., \& Clarke, V. (2006). Using thematic analysis in psychology. Qualitative Research in Psychology, 3(2), 77-101.

Brodie, I., \& Williams, V. (2013). Lifting the lid: Perspectives on and activity within student supervision. Social Work Education, 32(4), 506-522.

Collins, S., Coffey, M., \& Morris, L. (2010). Social work students: Stress, support and wellbeing. British Journal of Social Work, 40, 963-982.

Considine, T. Hollingdale, P., \& Neville, R. (2015). Social work, pastoral care and resilience. Pastoral Care in Education, 33(4), 214-219.

Criss, P. (2010). Effects of clients' violence on social work students: A national study. Journal of Social Work Education, 46(3), 371-390.

Davys, A., \& Beddoe, L. (2000). Supervision of students: A map and a model for the decade to come. Social Work Education, 19(5), 437-449.

Fletcher, D., \& Sarkar, M. (2013). Psychological resilience: A review and critique of definitions, concepts and theory. European Psychologist, 18(1), 12-23.

Forte, J.A., \& LaMade, J. (2011). The center cannot hold: A survey of field instructors' theoretical preferences and propensities. The Clinical Supervisor, 30(1), 72-94.

Fortune, A.E., Lee, M., \& Cavazos, A. (2007). Does practice make perfect? The Clinical Supervisor, 26(1-2), 239-263.

Fortune, A.E., \& Kaye, L. (2003). Learning opportunities in field practica. The Clinical Supervisor, $21(1), 5-28$.

Globerman, J., \& Bogo, M. (2003). Changing times: Understanding social workers' motivation to be field instructors. Social Work, 48(1), 65-73. 
Grant, L. (2014). Hearts and minds: Aspects of empathy and wellbeing in social work students. Social Work Education, 33(3), 338-352.

Grant, L., \& Kinman, G. (2012). Enhancing wellbeing in social work students: Building resilience in the next generation. Social Work Education, 31(5), 605-621.

Grant, L., \& Kinman, G. (2013). 'Bouncing back?' Personal representations of resilience of students and experienced social workers. Practice, 25(2), 349-366.

Grant, L., Kinman, G. \& Baker, S. (2015). 'Put on your own oxygen mask before assisting others': Social work educators' perspectives on an 'emotional curriculum'. British Journal of Social Work, $45,2351-2367$.

Grotberg, E. (1995). A guide to promoting resilience in children: Strengthening the human spirit. La Haya: Bernard Leer Foundation.

Halton, C. Murphy, M., \& Dempsey, M. (2007). Reflective learning in social work education: Researching student experiences. Reflective Practice, 8(4), 511-523.

Harr, C., \& Moore, B. (2011). Compassion fatigue among social work students in field placements. Journal of Teaching in Social Work, 31(3), 350-363.

Higgins, M. (2014). Can practice educators be a 'bridge' between the academy and the practicum? Journal of Practice Teaching and Learning, 12(3), 62-78.

Homonoff, E. (2008). The heart of social work: Best practitioners rise to challenges in field instruction. The Clinical Supervisor, 27(2), 135-169.

Hughes, M. (2011). Do challenges to students' beliefs, values and behaviour within social work education have an impact on their sense of well-being. Social Work Education, 30(6), 686-689.

Irish Association of Social Care Educators (2009). Practice placement manual. Retrieved from http://staffweb.itsligo.ie/staff/pshare/iasce/Placement\%20Manual\%2029mar09.pdf

Irish Association of Social Workers (2016). About social work. Retrieved from https://www.iasw.ie/

Kampen, J.K., \& Tamás, P. (2014). Overly ambitious: Contributions and current status of Q methodology. Quantity and Quality, 48, 3109-3126.

Kearns, S., \& McArdle, K. (2012). Doing it right? - accessing the narratives of identity of newly qualified social workers through the lens of resilience: 'I am, I have, I can'. Child and Family Social Work, 17(4), 385-394.

Kinman, G., \& Grant, L. (2011). Exploring stress resilience in trainee social workers: The role of emotional and social competencies. British Journal of Social Work, 41, 261-275.

Knight, C. (2001). The process of field instruction: BSW and MSW students' views of effective field supervision. Journal of Social Work Education, 37(2), 357-379.

Knight, C. (2010). Indirect trauma in the field practicum: Secondary traumatic stress, vicarious trauma and compassion fatigue among social work students and their field instructors. Journal of Baccalaureate Social Work, 15(1), 31-52. 
Lazard, L., Capdevila, R., \& Roberts, A. (2011). Methodological pluralism in theory and in practice: The case for Q in the community. Qualitative Research in Psychology, 8, 140-150.

Lefevre, M. (2005). Facilitating practice learning and assessment: The influence of relationship. Social Work Education, 24(5), 565-583.

Litvack, A., Mishna, F., \& Bogo, M. (2010). Emotional reactions of students in field education: An exploratory study. Journal of Social Work Education, 46(2), 227-243.

McAllister, M., \& McKinnon, J. (2009). The importance of teaching and learning resilience in the health disciplines: A critical review of the literature. Nurse Education Today, 29, 371379.

McSweeney, F. (2017). Supervision of students in social care education: Practice teachers' views of their role. Social Work Education, 36(1), 26-47.

Mason, J. (2002). Qualitative interviewing: Asking, listening and interpreting. In T. May (Ed.). Qualitative Research in Action. (pp. 225-41). London: Sage.

Miehls, D., Everett, J., Segal, C., \& du Bois, C. (2013). MSW students' views of supervision: Factors contributing to satisfactory field experiences. The Clinical Supervisor, 32(1), 128-146.

Nye, C. (2007). Dependence and independence in clinical supervision. The Clinical Supervisor, 26(12), 81-98.

O’Neill, E. (2009). Using professional supervision in social care. In P. Share \& K. Lalor (Eds.). Applied social care: An introduction for students ( $2^{\text {nd }}$ ed.) (pp.182-195). Dublin: Gill \& McMillan.

Palma-García, M., \& I. Hombrados-Mendieta, I. (2014). The development of resilience in social work students and professionals. Journal of Social Work, 14(4), 380-97.

Radley, M., \& Figley, C. (2007). The social psychology of compassion. Clinical S,

Rajan-Rankin, S. (2014). Self-identity, embodiment and the development of emotional resilience. British Journal of Social Work, 44(8), 2426-2442.

Simpson, D., Mathews, I., \& Crawford, K. (2014). Finding the perfect match: Pre-placement meetings in social work practice learning. Journal of Practice Teaching and Learning, 12(3), 44-61.

Shinebourne, P., \& Adams, M. (2007). Q methodology as a phenomenological research method. Existential Analysis, 18(1), 103-116.

Skehill, C. (2003). Social work in the Republic of Ireland: A history of the present. Journal of Social Work, 3(2), 141-159.

Social Care Ireland (2016). What is social care work? Retrieved from https://www.socialcareireland.ie

Staempfli, A, Kunz, R., \& Tov, E. (2012). Creating a bridge between theory and practice: Working with key situations. European Journal of Social Education, 22/23, 60-69.

Thompson, N. (2006) Promoting workplace learning. Bristol: The Policy Press.

Ungar, M. (2003). Qualitative contributions to resilience research. Qualitative Social Work, 2(1), 85-102. 
Vågstǿl, U., \& Skǿien, A.K. (2011). A learning climate for discovery and awareness: Physiotherapy students' perspective on learning and supervision in practice. Advances in Physiotherapy, 13, 7178.

Wilson, G. (2013). Evidencing reflective practice in social work education: Theoretical uncertainties and practical challenges. British Journal of Social Work, 43, 154-172.

Wilson, G., \& Kelly, B. (2010). Evaluating the effectiveness of social work education: Preparing students for practice learning. British Journal of Social Work, 40, 2431-2449.

Wilson, G., O'Connor, E., Walsh, T., \& Kirby, M. (2009). Reflections on practice learning in Northern Ireland and the Republic of Ireland: Lessons from student experiences. Social Work Education 28(6), 631-645. 